\title{
Proposals for Environmental Noise Management Boost at a National Level in the European Union Member States
}

\section{Zanda Krukle}

University of Latvia, Ministry of Environmental protection and regional development of the Republic of Latvia, Peldu 25, Riga, LV-1494, Latvia, e-mail: zanda.krukle@varam.gov.lv

\section{Ruta Bendere}

Institute of Physical Engineering, Aizkraukles 21, Riga, LV-1006, Latvia, e-mail: bendere@edi.lv

\section{$\Gamma$ crossef http://dx.doi.org/10.5755/j01.eis.0.11.18133}

Environmental noise is currently becoming one of the most dominant types of environmental pollution. The effects of noise closely correlate with quality of life especially regarding the physical and psychological health of inhabitants, social and economic costs, thus impacting the sustainable development of a country. Environmental noise management, therefore, is one of the most exigent tasks for environmental pollution management. The management of noise need to be developed in a comprehensive, integrative and cross-sectorial way, and appropriate methods and approaches for the management of noise impacts need to be found to deal with them in the most effective and sustainable manner at different governance levels, including national level that takes into account not only the requirements of the unions the country is a part of but also finds tailor made approaches.

Taking into account above mentioned, the aim of this research is to study environmental noise management at a national level, taking into account the framework in the European Union (hereinafter - EU). The objectives of this research are as follows: (1) to justify the need for development of environmental noise management, based on theoretical studies of environmental noise as a comprehensive environmental pollution component; (2) to analyze the established legislative and institutional practices for noise management in EU; (3) to analyse the problem situations detected in previous authors' researches carried out in Latvia (that is as an example of EU member state); (4) to propose improvements for noise management processes at a national level in Latvia. Research mostly focuses on EU member states that joined EU after the year 2000, including Baltic countries.

In the scope of the study authors analyze legislation and the institutional system for environmental noise management, and provide conclusions from Latvian case studies regarding practical implementation issues of environmental noise management. The conclusions from the studies allow providing suggestions for improvements at a national level by developing Latvian environmental noise management model. The model consists of the complex of processes that are used in practice at a national level: development of legislation and policy, noise mapping and action planning, control and complaints management, data and information collection, analysis and dissemination, and environmental impact assessment. The research allowed providing proposals for the improvements and further development

\section{Abstract}

Proposals for Environmental Noise Management Boost at a National Level in the European Union Member States

Submitted 04/2017

Accepted for publication 08/2017

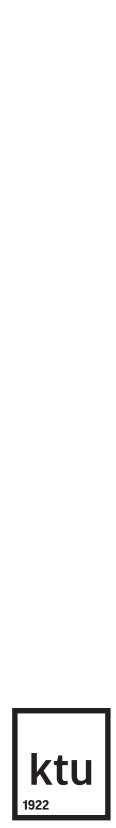

European Integration Studies No. $11 / 2017$ pp. $199-210$ DOI 10.5755/j01.eis.0.11.18133 (c) Kaunas University of Technology 
of these processes. The innovative aspects of this research are related to the description of the practice based management model and the development proposals.

KEYWORDS: environmental noise, management, improvement, national level, European Union, Latvia.

Introduction
Environmental noise is currently second most important types of environmental pollution after air pollution. The main noise sources are transportation, industry and different community activities. In the EU-27 countries almost 34 million people are exposed to long-term average traffic noise levels exceeding $50 \mathrm{~dB}(\mathrm{~A})$ and in average $72 \%$ of inhabitants think that noise is an important environmental stressor (European Commission, Directorate-General for Mobility, 2013).

The effects of environmental noise closely correlate with quality of life with quality of life regarding physical and psychological health, social and economic factors. The most significant noise affects sleep. This includes arousals, awakenings, longer falling-asleep periods, insomnia and other effects. Researches on sleep disturbance indicate a correlation between sleep disturbance, noise sources and noise perception place (Hume et al., 2012; Perron et al., 2016). A study conducted in Oslo showed significant relationships between noise annoyance at night and sleeping problems, as well as strong links between these factors and pseudo neurological complaints (Fyhri \& Aasvang, 2010). Studies on the subject confirm noise induced arousals even at relatively low noise level (Hume, et al., 2012). For example, research carried out in Sweden (Bluhm et al., 2004) has shown frequently occurring sleep disturbance for $23 \%$ of respondents at Leq24h level over $50 \mathrm{~dB}(\mathrm{~A})$, and $13 \%$ sleep disturbance complaints from respondents living in areas with at levels Leq24h level less than $50 \mathrm{~dB}(\mathrm{~A})$. In cases, when noise levels excess $55 \mathrm{~dB}(\mathrm{~A})$ during night time, this exposure can cause not only sleep disturbances, but also cardiovascular effects and also may increase stroke risk in the elderly (Hume, et al., 2012). Data form other traffic noise studies show that noise may be related to increased heart rate and therefore is a cardiovascular risk factor (Zijlema et al., 2016), hypo dynamic effects (Lekaviciute \& Argalasova-Sobotova, 2013), as well as increased hypertension (Bendokiene et al., 2011; (Lekaviciute \& Argalasova-Sobotova, 2013; Zeeba et al., 2017). Due to this, the World Health Organization has advised a target limit of outdoor night noise levels at an annual average of $40 \mathrm{~dB}(\mathrm{~A})$ (World Health Organization, 2009). But the EU requires the minimization of noise level in the areas where it exceeds $50 \mathrm{dBA}$ at night time and $55 \mathrm{dBA}$ daytime.

Apart from direct health effects noise pollution also causes annoyance can be viewed as an indicator of negative reactions to noise or interfered well-being, and may also contribute to the occurrence of the health issues mentioned above. Noise annoyance may be expressed as a variety of negative responses, such as anger, disappointment, dissatisfaction, withdrawal, helplessness, depression, anxiety, distraction, agitation, stress-related psychosocial symptoms such as tiredness, stomach discomfort and stress (WHO regional office for Europe, 2011). It must be highlighted that also psychological, social factors and sensitivity are very important in noise annoyance assessment (Fields et.al., 1997; Collette, 2011; Job, 1997), and only one-third of the variance of annoyance reactions can be explained by the acoustic properties (Guski, 1999).

Environmental noise also causes significant economic effects. These are related to increased amounts of medical expenses, productivity loss, absence from work, a decrease of property value as well as the costs associated with different noise control measures. The studies on how people value environmental conditions through the willingness-to-pay assessment. Most of the studies show the willingness-to-pay to be in a range from two to nine EUR, which is approximately $0.27-0.31 \%$ of total household annual income (Barreiroa, Sanchez, \& Viladrich-Grau, 2005). The impacts of noise also can be expressed in housing prices. Researches on airport noise exposure on housing prices show that the average noise depreciation index, which is defined as a loss in property value per one decibel change in noise exposure, is in average between $0.45 \%$ and 
$0.67 \%$ (Nelson, 2004) (Bristow \& Wardman, 2011). These impacts have to be taken into account when deciding on noise management policies.

Rapid urbanisation, industrialisation and growing mobility are the main factors contributing to increasing noise holistic health and economic impacts in developing countries (Schwela, Finegold, \& Stuart, 2011). Initially environmental noise was considered to be mainly a problem associated with the urban environment, however, expansion of business activities and infrastructure such as roads are becoming critical factors outside cities as well. It also must be taken into account that people living in the suburbs may have sought for quiet and better quality of life as it is in cities. In addition, if measures to reduce noise focus on control in "black spots" (such as airports and motorways), there are the corresponding increase in the moderate level "grey zones" (i.e. zones where the noise level is elevated but are yet bellow the threshold) (Buck, 2016). "Grey zones" therefore also should also be the focus of environmental noise management activities.

Taking into account above mentioned, environmental noise management as a set of measures comprising the development and implementation of outdoor noise control policy based on the identified problems, and assessment thereof, aims to prevent and reduce noise induced negative effects on human holistic health and well-being. Environmental noise management includes the development, implementation, and assessment of noise policy. In order to ensure noise management efficiency, noise management is organized at different levels that have different management focuses. The EU legislation sets requirements for noise management for agglomerations and the largest noise emitting facilities, and promote noise mapping and action planning, but national legislation regulates general and practical management aspects according to the factual general situation in a state and its specifics.

Different countries at a national level use different noise policy approaches with varying results, and there is no internationally coordinated global noise policy to reduce the wide-spread effects (Institute of Noise Control Engineering, 2006). Therefore practice adaptation could be one of the most urgent and useful tools for ensuring improvements in noise management. For example, in the EU member states, which joined the union in the last decade, environmental noise management has started to develop mostly only around the time of joining EU and integrating the requirements of the EU directives in the national systems (Belojevic et al., 2012). Compared to the other EU countries where noise management policies and schemes have developed steadily over the last decades of the previous century, significant developmental gaps in terms of approaches can still be identified. Also, a study of G.Licitra and E.Ascari (2014) about noise levels and noise annoyance, reveals that the highest values, that also correlates to highly annoyed and highly sleep disturbed inhabitants and a large part of higher values are detected in South and Eastern Europe. The authors believe that these countries should provide improvements through raising awareness on noise and health issues and improving national legislation. This coincides with the study of Jeram et al. (2013), where authors conclude that the public, in general, is not sufficiently aware of the noise hazards. This may be so due to the several reasons. First, noise is invisible; it does not provoke strong images and is perceived to be less hazardous. Second, noise is often labeled as a subjective issue, and not fully accepted as an environmental problem. Next, people not often clearly understand the scientific data for the connection between noise and health. Finally, people consider that financial matters prevail over environmental problems and may lack trust in authorities (Jeram et al., 2013). A similar conclusion was done by J. Hays, M. McCawley, and S.B.C. Shonkoff (2017), stating that profits and other economic considerations of noise causing activities are often weighed against environmental and health protection and other community concerns (e.g., nuisance, aesthetics, etc.). These issues are related not only to residents but also to policymakers that lack knowledge on the issue. Therefore noise management should 
become a concern of policymakers, their technical and staff from supporting agencies in order to estimate the effects and solve the issues relates to the environmental noise (World Health Organization, 2012). Other authors (King and Murphy, 2016) argue that environmental noise has already become a recognized issue, however, the data submitted to the EU environmental noise mapping, show that noise control remains on its current course, it may become more appropriate to refer to noise as 'the ignored pollutant'.

There is a set of noise management instruments - planning, technical, administrative, economic, communication, and legislative ones - that can be used for environmental noise management, however, analysis of the situation shows a need for improvements of their appliance for more effective noise control. For example, technical control tools are taken into account mostly for new and large projects; however, there is still little done to regard to retrofitting existing infrastructure (Moudon, 2009). Their increased role of the public in consultancy on noise actions plans, on landuse planning and environmental health impact assessment would be a step forward in improving public collaboration and awareness (Jeram et al., 2013).

\section{Methods and methodology}

In order to investigate environmental noise management, the assessment of noise management in EU member states was carried out. The study consist of three main parts: The objectives of this research are as follows: (1) analysis of the established institutional practices for noise management in EU; (2) analysis of the established legislative practices for noise management (3) analysis the problem situations detected in previous authors' researches carried out in Latvia and proposals for the improvements for noise management processes at a national level.

The study was based on:

- content analysis of literature and documentation. Literature and documentation review was done using the qualitative content analysis method. Content analysis of the documentation was carried out in order to gather information on noise management, impacting factors, approaches, theories, tools, etc. For this purpose information from scientific articles, conference materials, legislation, and planning documentation, books, reports and other sources were compiled.

the comparative analysis of environmental noise institutional models of European countries. This included preparation of institutional schemes and institutional function descriptions for each country chosen. This allowed mutual comparison of institutional system elements and functions. Institutional models were chosen on the premise that public policy is a product of the public institutions, which are responsible for its implementation. As the public policy applies to all members of the society, the institutional structure can have an important impact on the environmental noise policy. The institutional framework of several countries - Slovenia, Slovakia, Lithuania, Poland, Estonia, and Latvia - were compared and analyzed. These countries were chosen for the study because of their accession time to EU and in order to see how the recently formed noise management institutional systems are constructed and what noise management activities have been introduced in them. The example of those countries have is chosen in order to see how these countries develop and improve their noise management at a fast speed rate in order to aim towards the management level that the "older" EU countries have (i.e., countries in which noise management started to develop in previous century). This comparison is based on the analysis of institutional and functional differences between those countries. The chosen countries, in general, have similar noise sources and their structure apart from railway network technical characteristics $(1435 \mathrm{~mm}$ or $1524 \mathrm{~mm}$ gauge) and the typical industrial environment in Poland.

- content analysis of environmental noise legislation practice in three Baltic countries - Latvia, Lithuania and Estonia. It included the analysis of main legislative acts dealing with sectorial as- 
pects, i.e. environmental noise, its management, control, as well as cross - sectorial laws on transport, health and construction. This shows how the requirements of the European Commission Parliament and Council Directive 2002/49/EC (hereinafter - the Directive) on environmental noise assessment and management are taken into account and how the national noise management systems are constructed in order to take into account the local specifics and reach the general aim of the Directive - to protect society against noise. Deeper analysis exactly of the Baltic states' legislation is done because they have similar social and economic background.

data analysis from other researches carried out by authors on the practical implementation of environmental noise policy and legislation in Latvia and policy planning documentation analysis. These data were gathered in three Latvian case studies performed for the analysis of industrial, road and train noise management issues from the perspectives of inhabitants, environmental noise source managers, and public institutions, and through policy documentation content analysis. These case studies are not described in this article; however, the suggestions on environmental noise management in Latvia is based on the conclusions of those researches.

\section{Analysis of environmental noise legislation in EU}

One of the most important factors influencing environmental noise management is legislation and policy framework, which can be viewed as internal, i.e., national, and external, i.e., the one developed by state unions (EU, for example). The policy framework is the basis for noise management. Without proper policy and legislative framework, it would be difficult to develop and operate noise management programs actively or successfully and the prevention of problems in the environment which can be caused by the insufficient coordination of sectoral policies or local resolutions. (Cvetković \& Praščević, 2006; Praščević et al., 2013). At the level of EU, the legislation on noise control is developed based on the analysis of the issues identified in the member states, scientific data on the impacts and possible solutions. Member States have to transpose these regulations into their national legislation and implement them.

The main measures and legislative initiative for the mitigation of environmental noise pollution is the Directive which requires actions for the environmental noise prevention and reduction, development of strategic noise maps for major roads, railways, airports as well as urban agglomerations, in order to gather information on the noise level in a coordinated way, summarizing environmental pollution impacts from several noise sources, as well development of noise action plans. These action plans must include information on measures for the reduction of noise where it might be harmful and/or maintaining acoustical quality in quiet areas that should also be defined by the member states. Thus the Directive helps to implement the longterm EU pollution management strategy, which aims at reducing harmful health effects and number of people affected by noise in the longer term and provides a framework for developing existing environmental noise policy at national levels. To reach the goal, also other sectorial and cross-sectorial legislative acts and policy documents are prepared, including ones on transport and environmental impact assessment (hereinafter - EIA) for development activities.

To implement the EU regulations, countries have to develop subordinate legislation, i.e., to adopt the requirements, detect technical methods, set maximum permitted noise levels, and to prepare noise maps and action plans. However, each state can have its framework, strategy, and measures how to transpose the requirements at the national level. Different countries use different noise policy approaches with varying results, and there is no internationally-coordinated global noise policy to reduce the wide-spread effects (Institute of Noise Control Engineering, 2006). Therefore best practice adaptation is one of the most essential and useful tools for ensuring improvements in noise management. 
Factors as social behavior due to cultural differences, meteorological conditions, legislative backgrounds etc. determine different legislative approaches in the transposition of the Directive regulations (Lictra \& Ascari, 2015). The Directive also does not set the single approach for setting the environmental noise levels, therefore, Member states, taking into account above mentioned factors along with other factors such as territorial planning paradigms and the particular tailormade evaluation on noise sources choose their own approach to the legislation. When comparing the environmental noise levels in different EU member states, three main concepts on how the environmental noise levels can be identified - first, maximum noise levels are set for a particular territorial zone according to a spatial plan, for example, for multi-storey building, industrial areas or hospital zones different noise limits can be set. This concept is used in Latvia, Lithuania, and other countries. Second, maximum noise levels are source dependent. This means that different noise levels can be set for noise coming from transportation or industrial sites. The particular paradigm is used in Estonia, Spain, and other countries. The third alternative is the generic approach that refuses noise limits, but sets an ambitious policy aim on the matter, for example, to reduce the amount of noise affected inhabitants. This approach is used, for instance, in Finland that has a goal of $20 \%$ reduction of daytime noise over $55 \mathrm{~dB}(\mathrm{~A})$ compared to 2003 . Every approach has its advantages, and every country should have the tailor-made way of determination of noise limits so that they suit the actual situation best, most probably, based on the country's economical and urban structures. The first approach is mostly based on urban structures (population and economic activity concentration areas) and focuses of the possible vulnerability of the dwellers of residential parts of the area. This is well shown by the research of King et al. (2012) that proves that noise disturbance significantly impacts areas with a high population density and affects the inhabitants in their daily life, and that in residential areas noise levels tend to be lower than in mixed used areas. The second approach could be based on the correlation between annoyance and noise sources (Hume et al., 2012; Perron et al., 2016) and foresees protection of all inhabitants. The third approach is usually used for environmentally aware countries that are more ambitious in reaching sustainability goals. This approach requires very well coordination and impact assessment on the case-to-case basis.

The best practice seen in EU countries is noise limit value reduction, for example, that is planned in Cyprus, however, in some countries, particularly in Latvia, maximum permitted environmental noise values have been raised.

In order to compare environmental noise legislation in details, the law in Latvia, Lithuania, and Estonia was compared. The comparison on the legislative aspects is given in Table 1. As it can be seen in Table 1, all of the analyzed countries have transposed the requirements of the Directive in their

Comparison of Latvian, Lithuanian and Estonian noise management legislative framework

\begin{tabular}{|c|c|c|}
\hline Lithuania & Latvia & Estonia \\
\hline $\begin{array}{l}\text { Its legislation contains the most detailed } \\
\text { strategic noise management description: } \\
\text { _ It clearly provides noise management } \\
\text { principles and tools, defines indica- } \\
\text { tors for evaluation, describes the re- } \\
\text { sponsibilities and tasks for each insti- } \\
\text { tution involved, and requires annual } \\
\text { reports on noise management. } \\
\text { _ Lithuania's legislation contains the } \\
\text { most detailed information on control } \\
\text { procedures. }\end{array}$ & $\begin{array}{l}\text { The legislation has the } \\
\text { most detailed description } \\
\text { on procedural methods re- } \\
\text { lated to the implementation } \\
\text { of the Directive. } \\
\text { - The legislation lacks a par- } \\
\text { ticular description, which } \\
\text { defines the cooperation } \\
\text { among the different noise } \\
\text { managing institutions in } \\
\text { charge of controlling. }\end{array}$ & $\begin{array}{l}\text { - The legislation is ad- } \\
\text { equately developed in } \\
\text { that it has all the neces- } \\
\text { sary information about } \\
\text { noise management. } \\
\text { - Additionally, Estonia has } \\
\text { developed noise man- } \\
\text { agement guidelines on } \\
\text { how to implement legis- } \\
\text { lation in practice. }\end{array}$ \\
\hline
\end{tabular}

Source: Authors'. 
national legislative acts, but the each state has chosen different approach on drafting the legislation. For example, Lithuania legislation provides a detailed information for noise action implementation and policy monitoring afterward such as tasks, indicators, and evaluation mechanisms.

Latvian legislative acts provide a detailed procedural scheme, but Estonians have prepared noise management guidelines on how to implement legislation in practice (i.e. for noise evaluation and control) which have been sent to 150 municipalities. Estonian practice on guidelines could be considered to be a best practice that should be implemented in other states to specify the instruments of noise policy.

\section{Environmental noise institutional framework in EU}

The Directive requires states to assign responsibility to the relevant Authorities for the required implementation of the Directive, including the Authorities which ensure the data collection, development of noise maps and action plans, as well as their approval. However, each country needs an institutional system for implementing not only the requirements of the directive but also to ensure comprehensive environmental noise management in its different aspects. They include legislation and policy planning and implementation and its control. The research on institutional systems of Slovenia, Slovakia, Lithuania, Poland, Estonia, and Latvia allowed detecting five leading responsible institutions for noise management. These are Ministries (usually - Ministry of Health or Ministry on Environmental), agencies (usually Health Inspectorate or Environmental Inspectorate), municipalities, police (including municipal police), as well as noise consulting board or Noise consulting board in Lithuania and Slovakia. Ministries are responsible for the development of noise management legislation and policy. Agencies' tasks include control of noise limits in large infrastructure objects and dissemination of noise related information, but municipalities are responsible for the regulation of community activities and noise control in objects of municipal level significance. Violation control of community noise issues is usually devoted for police. But complementary recommendations on noise issues are given by Noise consulting board. This information on leading institutions allows creating a common noise management institutional framework for new EU member states. It consists of two levels - state level with ministry and agency sublevels, and municipal level. Noise consulting board is established only in Lithuania and Slovakia, but it could be a useful institutional component also in other countries if they lack noise expert networks. Noise consulting board was recognized as a useful instrument and can be advertised as a good example of inter-institutional collaboration. Noise consulting board could deal with the awareness raising on noise pollution issues and possible solutions in public and on the political agenda (organize press conferences, debates, etc.), and to provide advises and proposals on technical matters. The members of the Noise consulting board should be the responsible ministries, municipalities, and representatives of scientific, medical, acoustical and other public institutions that work for noise prevention.

\section{Environmental noise policy's practical implementation - the example of Latvia}

In order to investigate on how the environmental noise policy is practically implemented in EU, a detailed research in Latvia was done. The research included documentation studies and several case studies. The data and information gathered in the case studies that were explicitly analyzed in other scientific articles, showed insufficiently developed understanding of noise issues for both inhabitants and governors that causes lack of community-based environmental noise management and low noise management priority at both local and national levels, and leads to high level of subjective noise perception. See Table 2. 


\begin{tabular}{|c|c|c|}
\hline Table 2 & Problem group & Problem identified \\
\hline $\begin{array}{l}\text { Main problems of } \\
\text { environmental noise } \\
\text { management in Latvia }\end{array}$ & $\begin{array}{l}\text { Lack of community-based } \\
\text { environmental noise } \\
\text { management }\end{array}$ & $\begin{array}{l}\text { The public is not fully involved and its opinion on a potential source of } \\
\text { noise is not taken into account during the planning, construction and } \\
\text { operation processes. } \\
\text { Communication problems between municipalities and residents. }\end{array}$ \\
\hline & $\begin{array}{l}\text { High impact of subjective noise } \\
\text { perception aspects }\end{array}$ & $\begin{array}{l}\text { Development planning issues; } \\
\text { Communication problems; } \\
\text { Lack of information about noise, lack of analysis and data on national } \\
\text { problems. }\end{array}$ \\
\hline & $\begin{array}{l}\text { Low understanding of noise } \\
\text { issues and low policy priority/ } \\
\text { policy planning problems }\end{array}$ & $\begin{array}{l}\text { Often only the mandatory tasks are fulfilled; } \\
\text { Low application of noise management instruments; } \\
\text { Avoiding the usage of priority noise management measures; } \\
\text { Uncooperative, unwelcoming attitude; } \\
\text { Noise issues are usually treated as a low priority. }\end{array}$ \\
\hline & $\begin{array}{l}\text { Policy implementation } \\
\text { problems }\end{array}$ & $\begin{array}{l}\text { Often only the mandatory tasks are fulfilled; } \\
\text { Low application of noise management instruments; } \\
\text { Avoiding the usage of priority noise management measures; } \\
\text { Problems in implementation mechanisms; } \\
\text { Weak control; } \\
\text { Lack of guidelines, educational tools. }\end{array}$ \\
\hline & $\begin{array}{l}\text { Differences between large and } \\
\text { small size municipalities }\end{array}$ & $\begin{array}{l}\text { Small municipalities tend to act with less initiative and not always solve } \\
\text { the noise issues in optimal ways. }\end{array}$ \\
\hline
\end{tabular}

Source: Authors'.

In order to see how the situation could be improved in a coordinated, sustainable and integrative way, national level functions and processes at ministry and agency sublevel in Latvia were analyzed together with the conclusions of the case studies and legislative and institutional practice from other EU countries.

National level processes include six main environmental noise management processes that correspond to the primary functions of both state level sublevels - the ministry and agency sublevel. The first three processes describe the ministries' duties, but the rest - the agency sublevel. Those processes are:

Development of legislation in the field of environmental noise. According to the studies carried out, the existing regulations do not specifically promote or oblige the application of scientific and best practice based approaches. This is justified by several examples, such as increasing of maximum permissible noise levels or noise evaluation methods set in the national legislation. In order to improve the quality of the legislation, it would be necessary to provide officials with an access to scientific databases, to raise institutional capacity and to highlight the need of education and consultancy services. The latest factor can be solved through the creation and involvement of a new consulting body - a noise consulting board that could provide expert advice in specific and ambiguous cases. In this way also best practice from other countries can be transferred and implemented. The research also revealed the need of adding a new procedural step after the enactment of the applicable legal acts, i.e., for the development of methodological tools (such as guidelines) for involved parties, as it is already done in Estonia. These materials should explain the regulation set in the legislative act and assist in the implementation of regulatory requirements. The guidelines should be written as simplified explanations and descriptions of the applicable processes. 
Development of environmental noise policy. Environmental noise policy development process is done in accordance with the existing legislation. However, similarly, it would be necessary to raise knowledge and competence on the issue of those state officials who are responsible for develop the respective policy planning documents as well as to raise the public's awareness on noise-related environmental issues. Whenever noise related aspects are integrated into policy planning documents, information on the planned measures for noise abatement or prevention should be provided and include information on the funding sources, time frame, as well as indicators for the assessment of the progress in the context of this document. It is also necessary to involve the public fully and truly in the planning document's public review process, and therefore it is proposed that planning documents should be reviewed also by the Noise Consulting Board that could give competent opinion regarding noise aspects. Besides that, the planning document should be monitored and assessed regularly and the government informed.

- Development of environmental noise mapping and action plans. The process of developing environmental noise mapping and action plans is done in accordance with the legislation. However, there are some shortcomings in the process, which is not only due to failure to comply with the set time-frame as well as lack of data and ineffective adaptation of methods, but mostly with the implementation of the developed strategies. This is because both - the EU and the national levels - do not apply penalties in case of failure to implement the plan, as well as due to the limited possibilities to get funding for noise abatement projects. There is a need to link the noise action plans with other planning documents and budgetary documents to ensure the actions that are foreseen are actually implemented. There are also no guidelines for mapping and action planning that could save the resources of the institutions and ensure the use of streamlined approaches. According to the practice in Lithuania, the Noise Consulting Board should be involved in the assessment of the noise maps and action plans by giving its recommendations and annually assessing the progress of the implementation of action plans, and giving the report and recommendations.

Environmental noise control and complaints management. The investigation on complaints and noise level controls by the responsible institution - State Health Inspection - is currently done only when receiving complaints. However, it would be advisable to have annual inspection plans for the largest or new noise emitting objects as well as to ensure permanent noise monitoring in noise sensitive areas such as hospitals, etc. or to request the developer to submit certified noise measurement data. In addition, according to the suggestions for the EIA process improvements, the State Health inspection should carry out environmental noise assessment follow-up checks when the object subjected to the EIA procedure is commissioned and operating. The follow-up check should be done during the warranty period in order to ask the constructor to solve the issue in case the noise level is exceeded.

_ Data and information collection, analysis, and dissemination. The collection, compilation, analysis, and dissemination of the data and information on environmental noise are necessary to ensure timely and representative information on the situation in the country. Availability of data is a precondition for making a more accurate assessment of noise and its effects to develop appropriate and adjusted legislation, planning documents, guidelines, etc. Not only data and information should be gathered according to the EU regulatory requirements for data collection and reporting, but also research on environmental noise and public health issues should be carried out. So far studies on noise and its effects on the society have rarely been made by the responsible noise managing or scientific institutions in the Latvia. In case of establishing the Noise Consulting Board, it should review, collect the data and studies and give proposals for researches.

- EIA. During the EIA process, it is necessary to ensure that the process is performed in accordance 
with the applicable regulations. For objects that can potentially cause noise pollution and are close to residential or noise sensitive, or quiet areas, the EIA program must include noise assessment, including noise mapping. According to the results of a case study of Saulkrasti bypass construction and the associated noise annoyance due to subjective aspects of noise perception, Construction Board must inform the State Health Inspectorate or municipality about the start of the object's operation. During the object's warranty period, the State Health Inspectorate or local municipality should ensure noise assessment and control in accordance with the process of noise control and complaints management. This would help control the noise level and evaluate the applied measures, and ensure that, if the noise level is exceeded or the measures do not correspond to the EIA report, the construction warranty shall be used for the anti-noise measures.

\section{Conclusions}

Noise is an environmental pollutant that has effects on human well-being (including health and economic aspects), and that has to be managed in the sustainable and comprehensive way at different management levels. When analyzing environmental noise institutional system in EU, it can be seen that the Noise consulting Board and municipal inspectorate are good practice examples, which could be a useful noise institutional model component for other countries. Also, guidelines, indicator system and national policy with an aim to reduce the number of affected inhabitants, is best practice. Noise management deficiencies in Latvia are mainly due to the lack of community-based activities regarding noise management, high impact of subjective noise perception, low understanding of issues and low priority for implementation of the noise management policies. Noise management process improvements are related to the development of new intermediate body - Noise consulting board -, development of methodological tools, extending noise control as well as adding new procedural steps in the processes of EIA, development planning, object construction, noise mapping and action planning, development of legislation and others. Noise is an environmental pollutant that has effects on human wellbeing (incl. health and economic aspects), and that has to be managed in sustainable and comprehensive way at different management levels.

\section{References}

Lekaviciute, J., Argalasova-Sobotova L. (2013). Environmental noise and cardiovascular disease in adults: Research in Central, Eastern and South-Eastern Europe and Newly Independent States. Noise \& Health, 15, 22-31. https://doi.org/10.4103/1463-1741.107153

Barreiroa, J., Sanchez, M. \& Viladrich-Grau, M. (2005). How much are people willing to pay for silence? A contingent valuation study. Applied Economics, 37, 1233-1246. https://doi. org/10.1080/00036840500123234

Belojevic, G., Kim, R. \& Kephalopoulos, S. (2012). Assessment of needs for capacity-building for health risk assessment of environmental noise: case studies. Copenhagen: World Health Organization

Bendokiene, I., Grazuleviciene, R. \& Dedele, A. (2012). Risk of hypertension related to road traffic noise among reproductive-age women. Noise \& Health, 55, 371-377.

Bluhm, G., Nordling, E. \& Berglind, N. (2004). Road traffic noise and annoyance--an increasing environmental health problem. Noise \& Health, 24(6), 43-49.
Bristow, A. L. \& Wardman, M. (2011). A meta-analysis of stated preference studies of noise nuisance Proceeding of the 10th International Congress on Noise as a Public Health Problem. London, England: ICBEN

Buck, C.R. (2016). Shhh! Noisy cities, anti-noise groups and neoliberal citizenship. Journal of Sociology, 52(2), 190-203. https://doi. org/10.1177/1440783313507493

Cvetković, D., Praščević, M. (2006). Strategic directions in implementation of evironmental noise directive in international and national legislation. Facta Universiatis, 4, 21-34.

Collette, J.D. (2011). Self-Reported Aircraft Noise Complaints and Socioeconomic Demographics in the Greater Philadelphia Region: A Survey of Complaint Data from 1997 to 2009. Journal of Aviation Technology and Engineering, 1(1), 42-54

European Commission, Directorate-General for Mobility. (2013). Special Eurobarometer 406. At- 
titudes of Europeans towards urban Mobility. European Commission. Retrieved May 1, 201, from https://ec.europa.eu/transport/sites/transport/ files/themes/urban/doc/ump/flash-eurobarometer-ump-2013.pdf

Guski, R. (1999). Personal and social variables as co-determinants of noise annoyance. Noise $\&$ Health, 1(3), 45-56.

Hume, K., Brink, M., Basner, M. (2012). Effects of environmental noise on sleep. Noise \& Health, 14, 297 302. https://doi.org/10.4103/1463-1741.104897

Fields, J.M., de Jong, R., Brown, A.L., Flindell, I.H., Gjestland, T., Job R.F., et al. (1997). Guidelines for reporting core information from community noise research surveys. J Sound Vib, 206, 685-695. https://doi.org/10.1006/jsvi.1997.1144

Fyhri, A. \& Aasvang, G. M. (2010). Noise, sleep and poor health: Modeling the relationship between road traffic noise. Science of the Total Environment, 21(408), 4935-4942. https://doi.org/10.1016/j.scitotenv.2010.06.057

Institute of Noise Control Engineering. (2006). A global apprach to noise control policy. Noise Control Engeneering, 5(54), 258-346.

Jeram, S. Lekaviciute, J., Krukle, Z., Argalasova-Sobotova, L., Ristovska, G., Paunovic, K., Pawlaczyk-Luszczynska, M. (2013). Community response to noise: research in Central, Eastern and South-Eastern Europe and Newly Independent States. Noise \& Health, 15,12-21. https://doi. org/10.4103/1463-1741.107148

Job, R.F. (1999). Noise sensitivity as a factor influencing human reaction to noise. Noise Health, 1 , 57-68.

King, E.A., Murphy, E. (2016). Environmental noise - 'Forgotten' or 'Ignored' pollutant?. Applied Acoustics, 112, 211-215. https://doi.org/10.1016/j. apacoust.2016.05.023

King, G., Roland-Mieszkowski, M., Jason, T., Rainham, D.G. (2012). Noise Levels Associated with Urban Land Use, J Urban Health, 89(6), 1017-1030. https://doi.org/10.1007/s11524-012-9721-7

Licitra, G., Ascari E. (2014). Gden: An indicator for European noise maps comparison and to support action plans. Science of The Total Environment, 482-483, 411-419. https://doi.org/10.1016/j.scitotenv.2013.07.014

Moudon, A. V. (2009). Real Noise from the Urban Environment: How Ambient Community Noise Affects Health and What Can Be Done About It. American Journal of Preventive Medicine, 37, 167 - 171. https://doi.org/10.1016/j.amepre.2009.03.019

Nelson, J. (2004) Meta-analysis of airport noise and hedonic property values. Journal of Transport Economics and Policy, 38, 1-27.

Praščević, M., Mihajlov, D., Cvetkovic, Gajicki, A., Holeček, N. (2013). Acoustic zoning and noise assessment. Applied Mechanics and Materials, 430, 244-250. https://doi.org/10.4028/www.scientific. net/AMM.430.244

Schwela, D., Finegold, L. \& Stuart, J. (2008). A strategic approach on environmental noise management in developing countries. Proceeding of the 9th International Congress on Noise as a Public Health Problem. Foxwoods, USA: ICBEN.

World Health Organisation. Regional Office for Europe Publications. (2009). Environment and health priorities. Environment and Health Performance Review, Serbia. Retrieved 20 April 2017 from http://www.bgcentar.org.rs/bgcentar/wp-content/uploads/2013/12/WHO-Environment.pdf

World Health Organisation regional office for Europe. (2011). Burden of disease from environmental noise - Quantification of healthy life years lost in Europe. Retrieved 20 April 2017 from http://www.euro.who.int/__data/assets/pdf_ file/0008/136466/e94888.pdf

Perron, S., Plante, C., Ragettli, M.S., Kaiser, D.J., Goudreau, S., Smargiassi, A. (2016). Sleep Disturbance from Road Traffic, Railways, Airplanes and from Total Environmental Noise Levels in Montreal. Int. J. Environ. Res. Public Health, 13(8), 809. https://doi.org/10.3390/ijerph13080809

Zeeba H., Hegewald, J., Schubert, M., Wagner, M., Drögec, P., Swart, E., Seidler. (2017). A Traffic noise and hypertension - results from a large case-control study. Environmental Research, 157, 110-117. https://doi.org/10.1016/j.envres.2017.05.019

Zijlema, W., Cai, Y., Doiron, D., Mbatchou, S., Fortier, I., Gulliver, J., de Hoogh, H., Morley, D., Hodgson, S., Elliott, P., Key, T., Kongsgard, H., Hveem, K., Gaye, A., Burton, P., Hansell, A., Stolk, R., Rosmalen, J. (2016). Road traffic noise, blood pressure and heart rate: Pooled analyses of harmonized data from 88,336 participants. Environmental Research, 151, 804-813. https://doi.org/10.1016/j. envres.2016.09.014

Hays, J., McCawley, M., Shonkoff, S.B.C. (2017). Public health implications of environmental noise associated with unconventional oil and gas development. The Science Of The Total, 580, 448-456. https://doi.org/10.1016/j.scitotenv.2016.11.118 


\section{About the}

\section{authors}

\section{KRUKLE ZANDA}

Msc Env.

University of Latvia, Ministry of Environmental protection and regional development of Latvia

Fields of research interests

Environmental policy

\section{Address}

Peldu street 25, Riga, Latvia,

Tel. +37166016713

\section{BENDERE RUTA}

\section{Doc., Dr. Phys}

Institute of Physical Engineering

Fields of research interests

Waste and environmental pollution

\section{Address}

Aizkraukles 21, Riga, LV-1006, Latvia,

Tel. +37129171599 